\title{
Mediación pedagógica del aprendizaje a partir de la pregunta generadora en la educación media: Aprendizaje basado en proyectos
}

\author{
Pedagogical Mediation of Learning From a Generating Question in Secondary School. \\ Project-Based Learning
}

\section{Mediação pedagógica da aprendizagem partindo da pergunta geradora no ensino médio: aprendizagem baseada em projetos}

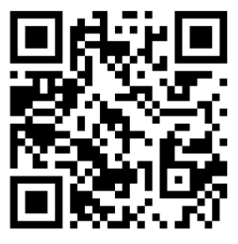

\author{
Milagro Obando-Arias \\ Instituto Dr. Jaim Weizman \\ San José,Costa Rica \\ milagro.oa@gmail.com
}

https://orcid.org/0000-0003-2693-2431

Recibido • Received • Recebido: 24 / 07 / 2019

Corregido • Revised • Revisado: 27 / 03 / 2021

Aceptado • Accepted • Aprovado: 23 / 04 / 2021

\begin{abstract}
Resumen: Los modelos de mediación pedagógica pretenden devolver el protagonismo a la persona en sus procesos de aprendizaje, de forma que se aleje de un rol pasivo y receptor. Con esta premisa, el presente trabajo tiene por objetivo desarrollar y analizar estrategias desde un modelo de mediación pedagógica, en donde se utiliza la pregunta generadora como elemento clave en el proceso de aprendizaje. A partir de ese objetivo, se puede responder a la inquietud de cuáles son los alcances pedagógicos posibles de construir, cuando las preguntas generadoras surgen del estudiantado. Esta interrogante orientó el proceso realizado durante el primer semestre del año 2019, con estudiantes de enseñanza media, específicamente de séptimo y octavo años, dentro de los cursos de Estudios Sociales y Educación Cívica. El trabajo se realizó en el distrito de Mata Redonda, cantón de San José, Costa Rica. Esta investigación es de orden pedagógico, se basa en metodologías cualitativas propias de la investigación-acción pedagógica. Se fue construyendo mediante observación participante, sistematización de experiencias y reflexiones posteriores a los planeamientos didácticos. La persona que sintetiza este trabajo es docente a cargo de los cursos mencionados, por tanto, no se trata de una investigación externa. El análisis presente en estas páginas incluye ejemplos de actividades de mediación desarrolladas con los grupos de trabajo.
\end{abstract}

Palabras claves: Mediación pedagógica; aprendizaje basado en proyectos; preguntas; creación de preguntas; preguntas generadoras; habilidades pedagógicas; aprendizaje; escuela secundaria. 
http://doi.org/10.15359/ree.25-2.21

http://www.una.ac.cr/educare

educare@una.ac.cr

\begin{abstract}
Pedagogical mediation models intend to return protagonism to students in their learning processes, pulling them away from a passive and receiving role. Based on this premise, the following work aims to develop and analyze strategies from a pedagogical mediation standpoint, in which a generating question is used as a key element in the learning process. From this aim, the question of which pedagogical scopes can be defined is answered when the generating question comes from the student body. This query led the process applied during the first semester of 2019, with secondary school students, specifically from seventh and eighth grade, in the Social Studies and Civic Education courses. This work was conducted in the district of Mata Redonda, canton of San José, Costa Rica. This pedagogical order research was based on qualitative methodologies proper to the pedagogical action research. It used participant observation, systematization of experiences, and further reflection upon the didactic planning. The teacher who synthesized this work was in charge of the courses mentioned above; therefore, this was not an external investigation. The analysis in the following pages includes examples of mediation activities developed with the workgroups.
\end{abstract}

Keywords: pedagogical mediation, project-based learning, questions, question creation, generating questions, teaching skills, learning, high school

Resumo: Os modelos de mediação pedagógica visam devolver o protagonismo à pessoa nos seus processos de aprendizagem, para que ela se afaste de um papel passivo e receptivo. Sob essa premissa, o presente trabalho visa desenvolver e analisar estratégias partindo de um modelo de mediação pedagógica, onde a questão geradora é utilizada como elemento-chave no processo de aprendizagem. A partir desse objetivo, é possível responder à preocupação de quais são os âmbitos pedagógicos que podem ser construídos, quando as questões geradoras surgem do corpo discente. Essa questão orientou o processo realizado no primeiro semestre do ano de 2019, com estudantes do ensino fundamental, especificamente sétimo e oitavo ano, nos cursos de Estudos Sociais e Educação Cívica. $O$ trabalho foi realizado no distrito de Mata Redonda, municipio de San José, Costa Rica. Esta pesquisa é de ordem pedagógica, baseia-se em metodologias qualitativas próprias da pesquisa-ação pedagógica. Foi construído através da observação de participantes, sistematização de experiências e reflexões após os planejamentos didáticos. A pessoa que sintetiza este trabalho é a professora responsável pelos cursos mencionados, portanto, não é uma investigação externa. A análise apresentada nestas páginas inclui exemplos de atividades de mediação realizadas com os grupos de trabalho.

Palavras-chave: Mediação pedagógica; aprendizagem baseada em projetos; perguntas; perguntas geradoras; criação de perguntas; habilidades pedagógicas; aprendizagem; ensino fundamental.

\title{
Introducción
}

En los ambientes pedagógicos, la presencia de la pregunta es algo que se da por un hecho. Pero esa misma presencia cotidiana hace que pocas veces se le preste la atención debida como elemento de reflexión, orientación y replanteamiento de lo que sucede en las aulas, e incluso fuera de ellas. Algunas metodologías para el aprendizaje, como la basada en proyectos, inician con una pregunta creada por la persona docente, la cual denominan como generadora. Las 
siguientes páginas reúnen la reflexión pedagógica focalizada en el potencial de la pregunta generadora, dentro de un modelo teórico práctico de mediación pedagógica, cuando la interrogante es creada por el grupo y no por la persona a cargo de este mismo.

Esta reflexión se da gracias a la sistematización de experiencias producida en ese sentido, con grupos de séptimo y octavo años de enseñanza secundaria. A través de observación y participación cotidiana con el estudiantado, se va perfilando un concepto de pregunta generadora, un proceso para la deconstrucción/construcción de sus características y la reflexión sobre la transformación pedagógica que implica. Los aspectos medulares sintetizados incluyen reseñas de las actividades de mediación implementadas, así como las preguntas generadoras que se crearon, aportando a la comunidad docente ejemplos susceptibles a mejoras, aplicación y adaptación, según los diversos grupos y áreas de trabajo.

Esta necesidad ha sido identificada en otras realidades latinoamericanas, por equipos dispuestos también a trabajar en nuevas pedagogías que promuevan cambios esperados. Por ejemplo, en Colombia, desde el año 2004, existe una iniciativa gubernamental denominada Ondas. Este programa tiene como objetivo la promoción del interés por los procesos investigativos, tanto en la infancia como en la adolescencia, a través de las experiencias escolares. Como parte del programa, se ha sistematizado material, teórico y práctico, en una serie de cuadernos conocidos como Caja de herramientas para maestros y maestras Ondas. Dentro de este programa la persona docente es vista "como acompañante de la investigación de los grupos infantiles y juveniles y facilitador de aprendizajes y capacidades durante su desarrollo" (Mejía y Manjarrés, 2011, p. 3).

Se trata, entonces, de un programa inserto en la perspectiva de la mediación, en lugar de la instrucción. Sin embargo, para efectos de lo expuesto en el presente trabajo, es oportuno establecer un distanciamiento con algunos de los postulados de Ondas, cuando se propone que "la investigación ... es una actividad que siempre estuvo en el mundo adulto y hoy aparece claramente en el de los niños, niñas y jóvenes colombianos como una práctica que es trasladada a múltiples ámbitos de la sociedad" (Mejía y Manjarrés, 2011, p. 26). Esta divergencia será retomada en las reflexiones de conclusión, una vez sea compartida la experiencia pedagógica de forma integral.

\section{¿Quiénes y con qué propósito plantean las preguntas?}

Con el fin de poder orientar un proceso de mediación pedagógica, a partir de preguntas generadoras, se requiere indagar cuál es ese valor que se puede dar a la pregunta dentro del ámbito pedagógico. Es fácil asociar la pregunta con la interrogante, la duda, que puede ser desde un dato concreto hasta planteamientos que generen mayor profundidad de análisis. En el contexto del proceso que ocupan estas páginas, el planteamiento parte desde la pedagogía de la pregunta que plantea Freire y Faundez (2013), la cual rescata ese valor de la curiosidad 
http://doi.org/10.15359/ree.25-2.21

http://www.una.ac.cr/educare

educare@una.ac.cr

en los procesos de construcción del saber. Desde esa mirada en la cual el saber se asocia con poder, surge la pregunta como un acto democrrático en los distintos espacios de aula, preguntas que serán planteadas por el estudiantado, a partir de la observación de la realidad en la que forman parte. En la obra dialógica sobre pedagogía de la pregunta, que Freire y Faundez (2013) desarrolló en colaboración con Antonio Faundez, el brasileño hace una invitación a reflexionar en el infinitivo más que en el nombre, o sea, la acción sobre el concepto. Él invita a considerar el acto de preguntar como un estilo de vida, una manera de vivir en constante curiosidad e indagación.

La pregunta ha estado presente siempre, tanto en la escuela tradicional o escuela participativa; desde el conductismo o el constructivismo; ya sea concebida como recurso de instrucción o de construcción de los aprendizajes. Desde un paradigma emergente, donde el contenido curricular sea el pretexto para replantear los vínculos entre las distintas personas que se encuentran en el aula, la pregunta no debe ser ignorada. Por el contrario, es uno de los recursos a plantear, problematizar y construir, de manera constante, para agitar las aguas del conflicto en las aulas. Debe favorecer ese conflicto que genere el pensamiento crítico y propositivo, que a su vez permita la reflexión de las acciones y relaciones pedagógicas.

Tradicionalmente, en el ámbito de la educación, la pregunta ha sido utilizada como el recurso fundamental para la evaluación, en un modelo que responde al sistema de educación bancaria que ha sido discutido por Freire y Faundez (2013). La docencia pregunta y el estudiantado demuestra si tiene los fondos suficientes para garantizar su progreso, sin importar el momento de la evaluación al que se haga referencia (evaluación sumativa o formativa). Se pueden encontrar evidencias hasta en la literatura costarricense. Fallas (2012), en su obra, lo narró a través de su personaje, Marcos Ramírez, cuando el adolescente debía responder, prácticamente de memoria, a las preguntas que se encontraban en las fichas de evaluación, organizadas por áreas del saber. Quien se detiene, con mirada crítica, a leer esos relatos en la novela, posiblemente encuentre gran relación con las palabras de Freire y Faundez (2013): "cuanto más se'embrutece' la capacidad inventiva y creadora del educando, más se lo disciplina para recibir 'respuestas' a preguntas que no fueron hechas" (p. 78).

Sin embargo, lo que se hace ahora en muchas de las pruebas escritas, personalizadas o estandarizadas, siguen siendo preguntas de comprobación de conocimiento. Preguntas formuladas desde alguna instancia externa: una institución, un profesor o profesora, un comité de evaluación. Preguntas que buscan medir cuánto ha logrado almacenar el estudiantado con respecto a esos conocimientos depositados. Hoy día es difícil observar experiencias como las que fueron retratadas en Marcos Ramírez; quizá se ha modificado la forma, pero la esencia es la misma. En una investigación reciente, con docentes de secundaria del área de las ciencias naturales, el informe señala que "el cuerpo docente proponía guías de preguntas, donde lo que debía hacer el estudiantado era transcribir al cuaderno lo expuesto en el libro de texto" (LeónLeón y Zúñiga-Meléndez, 2019, p. 16). 
Nunca está de más hacer un viaje en la historia, para revisar el legado de los antiguos griegos. Es muy común observar y analizar, en el conocimiento compartido desde distintas áreas del saber, los aportes de la técnica socrática. Al respecto de Sócrates y su actuar pedagógico, Rocerau y Vilanova (2008) describen un "método centrado en el diálogo, y sobre todo en la interrogación" (p. 2) La investigación bibliográfica expone un ir y venir de cuestionamientos, entre el filósofo y sus discípulos, utilizado muchas veces para desarmar ideológicamente al interlocutor. Sin embargo, ese diálogo mediado por interrogantes, en lugar de desestabilizar al estudiantado, puede convertirse en oportunidades para que construyan argumentos, 0 bien, profundicen en sus reflexiones. Como apunta Rodríguez García (2016), "Sócrates puede ser llamado como el Maestro de la pregunta; con este recurso discursivo ... se orienta hacia la búsqueda de la verdad que habita en cada persona" (pp. 852-853).

El objetivo docente es orientar al estudiantado para que construya su conocimiento. Haciendo conexión con Sócrates, esa verdad buscada por sus discípulos es comprendida como las condiciones propias que subyacen en cada persona para construir su saber, para consolidar su conocimiento personal y aportar al conocimiento colectivo. Esa verdad que guíe hacia la participación activa de cada estudiante, en lugar de asumir una postura receptora de contenidos curriculares.

Al hacer referencia a Sócrates, se hace referencia a la mayéutica, cuyo objetivo es llevar al estudiantado al descubrimiento del conocimiento. Pero, al igual que toda actividad humana, es atravesada por relaciones de poder. "La mayéutica se constituye en un aporte pedagógico fundamental porque recrea la incertidumbre, la reflexión y el diálogo .... Sin embargo, es conveniente advertir que la mayéutica puede resultar un mecanismo inquisidor, discriminatorio y sectario" (Rodríguez García, 2016, p. 853). La llamada de atención debe llevar a la reflexión sobre el modo en que se vincule el uso pedagógico de la pregunta. El planteamiento que se haga de este recurso, en las comunidades de aprendizaje, también merece ser considerado en el análisis pedagógico de las mediaciones y actividades de aula.

\section{La pregunta en la metodología basada en proyectos}

De acuerdo con Thomas (2000), el aprendizaje basado en proyectos es una metodología para desarrollar el proceso de aprendizaje en las aulas. Se tiene un objetivo claro que define al proyecto, hay un interés compartido. El proceso de construcción para alcanzar ese objetivo está formado por experiencias o actividades, relacionadas entre sí. Para alcanzar dicho objetivo o producto final, los grupos de estudiantes participantes deben organizar su plan de trabajo y tareas a ejecutar, por lo cual se fomenta en el colectivo la toma de decisiones. Desde este enfoque, si bien es cierto se estimula el desarrollo de la autonomía, esta se logra dentro de la experiencia de trabajo colaborativo. Por su parte, Díaz Barriga Arceo y Hernández Rojas (2010) 
http://doi.org/10.15359/ree.25-2.21

http://www.una.ac.cr/educare

educare@una.ac.cr

señalan que en los proyectos se busca emplear"estrategias dirigidas a activar los conocimientos previos de los alumnos o incluso a generarlos cuando no existan ... para utilizar tal conocimiento como base para promover nuevos aprendizajes" (p. 87).

Esta metodología promueve la participación activa y el protagonismo del estudiantado; retoma principios teóricos que han sido ya expuestos, algunos con una significativa antigüedad. A través de los postulados, parece escucharse la voz de Decroly y sus centros de interés; la exposición de Dewey instando a brindar experiencias auténticas en las escuelas; surge de nuevo el aprendizaje por descubrimiento del que habló Montessori; o bien, las experiencias de convivencia pedagógica que desarrollaran Mistral y Vasconcelos en México.

En el presente siglo, dicha metodología se ha venido presentando al personal docente, en distintos contextos, a través de sesiones de capacitación, con el propósito de implementar las estrategias en las aulas. La sistematización de experiencias considerada para el presente trabajo abarca distintas sesiones, al ser parte del personal que recibió la instrucción, desde el año 2016 al 2018. En dicho programa de formación, se propone iniciar los procesos vinculados al aprendizaje basado en proyectos, a partir de una pregunta generadora. Las distintas referencias, que son tomadas del material compartido al personal docente, apuntan hacia las siguientes características para dichas preguntas:

- Se proponen al inicio de un tema por desarrollar.

- Su objetivo es facilitar el aprendizaje.

- Son planteadas por el personal docente al estudiantado.

Descritas de esta forma, no difieren mucho de las conversaciones introductorias que se realizan con los grupos de estudio, principalmente en las aulas de primaria. Este uso de la pregunta sigue centrándose en lo anotado párrafos atrás: la comprobación de conocimiento, en este particular, un conocimiento previo. Se trata de una acción exploratoria para determinar cuánto saben las personas acerca del tema. Por tanto, el uso de la pregunta desde el rol docente, aún en una metodología basada en proyectos, se mantiene dentro del sentido tradicional, donde el conocimiento y hasta la necesidad de este mismo siguen en poder del ser adulto.

Las observaciones son fundamentadas en la premisa del personal docente como creador de las preguntas. Es una muestra de lo que ya había sido denunciado por Freire y Faundez (2013), cuando señaló que "el autoritarismo que obstaculiza nuestras experiencias educativas inhibe, cuando no reprime, la capacidad de preguntar" (p. 70). La relación de poder en las aulas se establece de manera tan polarizada, que hasta el ejercicio mental que implica preguntar, está monopolizado por la perspectiva docente. Incluso en las metodologías que buscan más protagonismo del estudiantado, como es el caso de las basadas en proyectos. 
Por lo anterior, en el marco del proceso pedagógico realizado, no se desechan las propuestas desde un aprendizaje basado en proyectos. Lo que se ha resignificado es la construcción de la pregunta generadora en el proceso. Para lograrlo desde la práctica, se hace referencia al trabajo durante el primer semestre del año 2019, con grupos de enseñanza secundaria, específicamente en séptimo y octavo años. Los cursos se relacionan con el área de las ciencias sociales. En este caso, dentro del proceso del aprendizaje por proyectos, se replanteó el uso pedagógico de la pregunta. Para promover esta constante curiosidad en las aulas, en el paradigma que considera a la persona como constructora activa de su aprendizaje, la metodología basada en proyectos debe ofrecer espacios de indagación. Se requiere de procesos que activen ese compromiso aprendiente en cada persona. La pregunta generadora deberá, entonces, activar el interés en principio, para luego dirigirlo durante el tiempo en que se mantenga el proyecto. Como lo recuerdan León-León y Zúñiga-Meléndez (2019), "es necesario [crear] y practicar una educación donde el diálogo, [el] análisis crítico, el debate y las experiencias significativas sean prácticas fundamentales y diarias" (p. 7).

Para la construcción de este proceso, el accionar fue orientado por los siguientes principios pedagógicos:

- Preguntas como génesis del proceso. Se crean al principio del proyecto, no de un tema específico, por cuanto la metodología da lugar para incluir varios contenidos curriculares en una misma planificación.

- Pregunta con intención pedagógica crítica. Su objetivo radica en activar el interés de las personas participantes, a través de su propia curiosidad y necesidad de investigación.

- Pregunta como elemento para la mediación pedagógica. Son creadas por la población de estudiantes, en un proceso que puede ser mediado por la persona docente.

En el marco del trabajo realizado, la pregunta generadora pasa de ser una estrategia a una fase del proyecto, con experiencias pensadas para crearla. Se entenderá, entonces, por pregunta generadora, aquella que es creada por estudiantes, sea de forma individual o colectiva, y sintetiza el saber que se desea alcanzar a lo largo de las distintas etapas del proyecto. Esta pregunta orienta su curiosidad como una línea de investigación en medio de los contenidos curriculares que son incluidos, y presenta las siguientes características:

- Es abierta.

- Permite múltiples opciones en sus respuestas.

- Su planteamiento genera la posibilidad de crear un entramado de interrogantes durante el recorrido del proyecto. 
http://doi.org/10.15359/ree.25-2.21

http://www.una.ac.cr/educare

educare@una.ac.cr

\section{¿Pregunta generadora como recurso o como mediación?}

Dentro de los principios pedagógicos que han sido señalados, previamente, para orientar el uso de la pregunta, se ha propuesto que sea un elemento o punto de partida de la mediación pedagógica. En este contexto, se está comprendiendo la mediación pedagógica como un modelo en el que se deconstruyen y construyen las interacciones y el devenir entre docentes y estudiantes; entre enseñanza y aprendizaje. Por tanto, si el aprendizaje basado en proyectos es la metodología, a su vez se inscribe en un modelo, en una forma de comprender ese proceso humano construido por seres humanos: el proceso de construcción de conocimiento.

Cuando se menciona el concepto de mediación pedagógica, se hace referencia a un modelo "capaz de promover y acompañar el aprendizaje de nuestros interlocutores, es decir, de promover en los educandos la tarea de construirse y de apropiarse del mundo y de sí mismos" (Prieto Castillo, 2000, p. 29). El rol docente, entonces, se puede ver como una intervención, no para transmitir conocimientos, ya que se trata de motivar y orientar al estudiantado a que lidere su propio proceso de aprendizaje. En ese rol para la profesión docente, se comprende una manera particular en atender los distintos contenidos curriculares, "a fin de hacer posible el acto educativo, ... concebida como participación, creatividad, expresividad" (Gutiérrez Pérez y Prieto Castillo, 2004, p. 50).

Según este enfoque, el uso tradicional que se ha hecho de la pregunta como un recurso, deja de tener lugar. Un enfoque de mediación pedagógica exige, de la metodología basada en proyectos, que la pregunta sea creada por el estudiantado, no planteada por otra persona. El papel del personal docente se enfoca en la mediación del proceso. Es un acompañamiento que busca fortalecer las habilidades de investigación en cada participante, donde se estimule el pensamiento crítico a partir de interrogantes pertinentes. Exige, también, la propuesta de encuentros que estimulen al estudiantado a generar las preguntas esperadas.

Con estas premisas teóricas y la reflexión sobre ellas, se desarrolló el trabajo dentro de un aula de enseñanza media. Las acciones pedagógicas se realizan dentro de los cursos de estudios sociales y cívica, con grupos de sétimo y octavo años. El rol docente, dentro de esta mediación pedagógica, lo asume quien tiene asignados dichos cursos, para el año 2019. Por tanto, se ha enfocado desde el enfoque de la investigación - acción participativa (IAP) aplicado a la realidad de aula en un ámbito pedagógico formal. En este entendido, se ha considerado la experiencia docente dentro de la técnica de observación participante, durante el proceso del primer semestre del año ya mencionado. Se ha tomado como parte de los insumos el uso de la planificación quincenal, como recurso de sistematización de experiencias. De igual forma, se han registrado observaciones en sistematizaciones de los procesos desarrollados en el aula, con las personas participantes-estudiantes. Para los efectos del presente artículo, se han retomado cuatro de esas sistematizaciones, que se presentan en dos vías: mediación y reflexión. 
La mediación propuesta, en cada caso, reúne lo que fue observado y sistematizado durante la construcción pedagógica. Por su parte, la reflexión sistematiza las conclusiones y hallazgos más destacados, desde un sentido pedagógico particular en cada caso. Ha sido la intención no separar ese sentido pragmático y reflexivo que propone la IAP, donde las conclusiones no son cierres. Se trata de la apertura de otros ciclos de investigación acción.

\section{Mediación propuesta: Curso de Cívica en octavo año}

Una actividad breve, para recopilar datos u opiniones e introducir un tema particular, puede generar insumos importantes para el grupo de trabajo, de modo que cuente con la oportunidad de crear preguntas significativas para sí. En el curso de Cívica, para el nivel de octavo año, se incluye el tema de "Funciones del gobierno local." Para empezar a trabajar, el estudiantado se organizó en parejas, y debían abordar a distintas personas de la comunidad educativa con la siguiente pregunta: ¿Cuál es su gobierno local?

Dicha interrogante se formuló a estudiantes de secundaria, docentes de la institución, así como personas funcionarias del área administrativa. El estudiantado recogió la información mediante grabaciones de audio, aprovechando sus teléfonos móviles. Esta forma de registro puede ser modificada sin dificultad, adaptándose a los recursos institucionales con los cuales se cuente.

Durante la puesta en común, se expusieron las distintas respuestas registradas. De forma amplia, cerca del $45 \%$ de la población no precisó adecuadamente a su gobierno local. La discusión del grupo giró en que, al aplicar la medición en una institución educativa, esperaban que el porcentaje de desconocimiento fuera más bajo. Eso les llevó a inferir que si se aplicaba la encuesta de forma abierta, en un espacio público, con población diversa en términos de escolaridad, ese porcentaje podría ser más alto. Dentro de los elementos que más llamaron su atención, se puede mencionar:

- respuestas de personas adultas que mencionaron la municipalidad, pero no especificaron la localidad

- respuestas de estudiantes, en sus últimos años de secundaria, que no identificaron su gobierno local

En ese segundo aspecto, las personas entrevistadas mencionaron al partido político que ganó la última elección nacional, nombres de candidaturas, nombres de otros partidos nacionales, así como el partido que ganó las últimas elecciones estudiantiles en la institución. Luego de la discusión generada a partir de la información obtenida, se abrió una lluvia de ideas con preguntas generadoras del estudiantado. Este grupo, en particular, ya había tenido una experiencia anterior, por lo cual la mediación consistió en traer a la memoria colectiva los elementos característicos de las preguntas en cuestión. La pregunta que, finalmente, fue 
http://doi.org/10.15359/ree.25-2.21

http://www.una.ac.cr/educare

educare@una.ac.cr

elegida para trabajar a lo largo del proyecto, es posible distinguirla y comprenderla en medio de la experiencia compartida por el grupo, tanto dentro como fuera del aula: ¿Qué hizo o qué no hizo el gobierno local para que nadie lo recuerde? (octavo año)

\section{Reflexión pedagógica: Una pregunta puede crear y organizar puentes para el aprendizaje}

Uno de los principales argumentos que representan desafíos al momento de proponer metodologías activas, en donde la participación del estudiantado sea clave, se encuentra en el compromiso curricular. Parece que, a pesar de las discusiones, el contenido sigue pesando en cuanto a intereses. El plan curricular puede llegar a convertirse -si es que no lo es- en el único eje que mueve la actividad educativa. Esta condición bloquea, en muchas ocasiones, las iniciativas docentes por ejercer su labor desde el paradigma emergente, desde una pedagogía crítica. A este punto, se le puede dar importancia estratégica a la metodología basada en proyectos. Las personas docentes pueden abrir los espacios necesarios para una planificación que enlace varios contenidos, para problematizarlos y deconstruirlos en forma conjunta, desde una misma pregunta generadora.

La ganancia se da en los dos sentidos: esa misma pregunta, estructurada por el estudiantado y mediada desde la pedagogía, brinda la oportunidad de viajar a lo largo del proyecto, utilizando los contenidos programados como una especie de ruta de navegación, que les permita a todas las personas hacer sus espacios de construcción, actividad y reflexión para armar respuestas $y$, con ellas, su aprendizaje. Desde este punto de partida, es posible señalar que "la mediación construye puentes para el aprendizaje desde todos los horizontes de vida y de creación del ser humano" (Prieto Castillo, 2000, p. 33). Puentes que son dados por las conexiones estimuladas entre los distintos contenidos incluidos, que ayudan a responder inquietudes formuladas por el estudiantado en procesos de creación, lo cual generalmente va a vincularse con su vivencia: desde que es el estudiantado el que crea la pregunta generadora, está vinculando su persona en el proceso en el rol actor, más que receptor.

\section{Mediación propuesta: Curso de Estudios Sociales, séptimo año}

En el caso del grupo de séptimo grado, en el año anterior de su escolaridad habían conocido conceptos ligados al movimiento de La llustración. En otro de sus cursos (en el año presente) conocieron características de distintas formas de gobierno, incluida la monarquía absolutista. Considerando lo anterior, se inició una actividad para estimular esos conocimientos previos, a través del juego de charada. La Real Academia Española (2014) en su diccionario define la palabra charada como un "pasatiempo consistente en adivinar una palabra a partir de alguna pista sobre su significado y sobre el de otras que se forman con sílabas de la palabra buscada". Los términos usados en el juego fueron elegidos previamente como parte del proceso mediador; conforme iban siendo adivinados, se anotaban para facilitar la fluidez al conectar conceptos. Al 
finalizar el juego, se orientó al grupo a mencionar las situaciones o hechos históricos que se estarían incluyendo en el proyecto por iniciar. Estos eventos eran:

- La formación de los Estados absolutos

- La llustración y la Revolución Francesa

- La formación de las monarquías absolutas

- La llustración y el pensamiento científico-racional

- La Revolución Francesa

\section{Reflexión pedagógica: La creación de la pregunta como un ejercicio colaborativo}

Una vez delimitado el espacio conceptual con el cual trabajar, la construcción de la pregunta generadora se hizo de forma colectiva, con los aportes de cada participante, en un ejercicio de escritura y reescritura. Para el acceso colectivo a la información, se puede utilizar pizarra, proyección, papelógrafo, entre otros recursos. Así, en un trabajo colaborativo, lograron el siguiente producto: ¿Cómo se manifiestan las ideas de La llustración en el desarrollo de la Revolución Francesa, de modo que se afectaron otras monarquías? (séptimo año)

Cabe mencionar que el grupo en cuestión ya había vivido experiencias de aprendizaje, individuales, donde habían trabajado habilidades en la construcción de preguntas generadoras. La sistematización obtenida es insumo, también, para este trabajo, y se presentará en el apartado sobre la pregunta generadora para incentivar las habilidades de investigación.

\section{Mediación propuesta: Curso de Cívica, octavo año}

En este grupo se promovió la creación de la pregunta generadora, a partir de la exploración de conceptos, de igual forma que se desarrolló en la actividad anteriormente reseñada. La principal diferencia introducida consiste en la técnica de clase invertida, con cierto grado de trabajo individual desde la casa. Se les dio un listado de conceptos, relacionados con funciones, tanto del Tribunal Supremo de Elecciones como del Registro Civil (instituciones del entorno costarricense). Para efectos de esta realidad de grupo, ya tenían conocimiento sobre el Tribunal, pero no tanto en cuanto al Registro. Con el panorama conceptual compartido, la actividad en casa se basó en revisarlo, apropiarse de los significantes y, a partir de ellos plantear una pregunta generadora. En el aula las preguntas fueron colocadas en un mismo documento, para que, en equipos, las pudieran analizar, discutir $y$, al cierre de esa fase, votar por la pregunta que más reunía las características pertinentes y, en mayor grado, los intereses de los grupos. Esto produjo lo siguiente: ¿Cuál es la vinculación del Registro Civil con el Tribunal Supremo de Elecciones y de qué forma aporta a las personas de la sociedad costarricense? (octavo año) 
http://doi.org/10.15359/ree.25-2.21

http://www.una.ac.cr/educare

educare@una.ac.cr

\section{Reflexión pedagógica; Preguntas generadoras para incentivar las habilidades de investigación}

La oportunidad de realizar labores docentes, durante el primer semestre del 2019, tanto con grupos de séptimo y octavo, como de undécimo, abre espacios de reflexión para problematizar qué habilidades está desarrollando o no el estudiantado en las aulas. Hay gran dificultad para crear preguntas de investigación, en estudiantes de último año de su formación secundaria. En los procesos que deben realizar durante el curso lectivo, el personal docente observa en el estudiantado carencias en técnicas de investigación, en varias fases del proceso, que se evidencian desde el planteamiento de la pregunta de investigación. Las habilidades de pensamiento, al igual que otros aprendizajes de vida, no surgen de manera espontánea. Tampoco se puede esperar que el estudiantado, acostumbrado a trabajar con técnicas magistrales y de reproducción de contenidos, cuente con las destrezas necesarias para construir sus investigaciones, sin un alto grado de andamiaje. Es necesario que los espacios de construcción pedagógica, desde los primeros años de secundaria, e incluso desde la escuela primaria, contemplen la necesidad de formar y fortalecer esas habilidades dentro del mismo proceso de aprendizaje.

Como ya se había mencionado, en la mirada de estas páginas, no se ve la investigación como algo propio del mundo adulto que debe ser transferido a la niñez y la adolescencia. Lo que se busca es rescatar esa curiosidad propia de la infancia, que ha sido negada por los modelos de educación bancaria. Aunque el contexto otorga un enfoque académico al término"investigación", extraerlo de la vida integral y enmarcarlo en un área específica, puede generar división entre procesos y edades. Como parte del desarrollo de la persona, la investigación es un proceso que se emprende desde los primeros meses de vida, parte de la necesidad de conocer el entorno, establecer conexiones con él y apropiárselo. En una conversación con estudiantes de décimo año, dentro del curso de Teoría del conocimiento, se reflexionaba que en sus primeros años, la infancia es curiosa, una curiosidad natural y necesaria. Las personas conversaban, asimismo, que esa exploración era un proceso de investigación, mediado principalmente por los sentidos físicos, donde se construye conocimiento del medio a través de la percepción sensorial.

¿Dónde surge, entonces, la pérdida de este interés investigador, al punto de aparecer como algo propio de la vida adulta? Es, precisa y paradójicamente, el proceso de escolarización formal quien provoca esta separación. Freire y Faundez (2013) lo llamó "'castración de la curiosidad'. Es un movimiento unilineal. ... ¡El educador, en general, ya trae la respuesta sin que le hayan preguntado nada!" (p. 69). De ahí la importancia en promover proyectos orientados a responder una interrogante, que haya sido planteada por el estudiantado. El proceso, al inicio, puede ser difícil, pero con la mediación oportuna, así como la exposición frecuente a diversas actividades pertinentes, podrán empoderarse y apropiarse de la destreza. Si el estudiantado cuenta con la base para la creación de una pregunta generadora, habrá desarrollado estrategias 
metacognitivas que pueda implementar y transferir, luego, a las exigencias de otros procesos de investigación. Tanto quienes propusieron el concepto de mediación pedagógica, así como quienes desarrollan líneas de trabajo desde esa perspectiva, analizan y aprovechan este ámbito pedagógico para incentivar la búsqueda y la investigación en el estudiantado.

\section{Mediación propuesta: Proyecto interdisciplinario, Español y Estudios Sociales, séptimo año}

En la mediación compartida anteriormente, que desembocó en la pregunta sobre las manifestaciones del movimiento de La llustración en relación con las monarquías absolutistas de la época, se acotó que el grupo ya había trabajado en la creación de preguntas generadoras. Esa experiencia previa se dio dentro de un proyecto interdisciplinario. En el curso de Español habían leído, analizado y discutido un sesenta por ciento del libro autobiográfico La bailarina de Auschwitz, de Eger (2018) Ese análisis se enfocó en los procesos de narración incluidos en la obra, en los tres periodos de estudio que se proponen para este estilo de literatura: el antes, durante y después de los hechos del holocausto dado en el marco de la Segunda Guerra Mundial.

En el curso de Estudios Sociales, se planteó un trabajo de investigación bibliográfica, en donde el producto final fue un informe escrito de la investigación alcanzada. El trabajo se propuso en metodología individual, con posibilidades de intercambio de ideas, recursos, fuentes, especialmente en aquel estudiantado cuyos intereses temáticos convergían. Parte del proceso se orientó hacia la construcción de la pregunta generadora y una ruta de investigación, que fuera la guía del trabajo. León León (2014) señala que en la mediación pedagógica "el educador ... orienta intencionalmente la actividad" (p. 143). La orientación intencional no debe confundirse con la dirección magistral del proceso. Todas las acciones pedagógicas tienen intencionalidad; la reflexión debe llevar a descubrir esa intención, problematizarla y transformarla. Si se descubre que el estudiantado en años de educación secundaria llega al final de ese proceso con carencias en habilidades de investigación, de habilidades metacognitivas, debe orientarse la mediación pedagógica con intención de trabajar en esas áreas, en forma global durante los años de formación.

Tampoco se puede pretender que el estudiantado obtenga esas habilidades como si se pudieran comprar y agregar a sus saberes, sin ningún tipo de entrenamiento. Es común encontrar docentes que señalan las carencias en sus estudiantes, pero no procuran ajustar sus planificaciones para trabajar en esas áreas. Con miras en lo anterior, y para facilitar la mediación pedagógica del proceso, se diseñó una guía de trabajo. Esta se dividió en dos etapas, sistematizadas a continuación en las Figuras 1 y 2. Corresponden a un proceso de mediación para plantear preguntas generadoras. 
http://doi.org/10.15359/ree.25-2.21

http://www.una.ac.cr/educare

educare@una.ac.cr

Figura 1: Mediación para la introducción a preguntas generadoras. Proyecto interdisciplinario (Español/Estudios Sociales), sexto grado, noviembre 2018

\begin{tabular}{|c|c|c|}
\hline $\begin{array}{l}\text { Imagine que este es el tema en el que va a } \\
\text { realizar su investigación: }\end{array}$ & \multicolumn{2}{|c|}{ La comunidad colombiana en Costa Rica } \\
\hline $\begin{array}{l}\text { Para iniciar el proceso, se debe plantear una } \\
\text { pregunta generadora. Observe la siguiente: }\end{array}$ & \multicolumn{2}{|c|}{$\begin{array}{l}\text { ¿Cómo ha sido el proceso en el que se ha asentado en Costa Rica la actual } \\
\text { comunidad colombiana? }\end{array}$} \\
\hline \multicolumn{3}{|c|}{$\begin{array}{l}\text { Ahora, analice las características que debe tener una pregunta generadora. } \\
\text { Para eso, observe la pregunta ejemplo y explique, si cumple con cada uno de los tres rasgos importantes. }\end{array}$} \\
\hline \multicolumn{3}{|c|}{ Características importantes en una pregunta generadora: } \\
\hline Es una pregunta abierta & $\begin{array}{l}\text { Puede responderse de distintas } \\
\text { formas }\end{array}$ & $\begin{array}{l}\text { La pregunta permite crear una serie de } \\
\text { interrogantes relacionadas con ella }\end{array}$ \\
\hline \multicolumn{3}{|c|}{$\begin{array}{l}\text { Para comprobar la última característica elabore una lista de temas o lista de preguntas relacionadas. El propósito es generar } \\
\text { una lista de preguntas en secuencia, que ayuden a encontrar la respuesta a la investigación. }\end{array}$} \\
\hline \multicolumn{3}{|l|}{$\begin{array}{l}1 . \\
2 . \\
3 .\end{array}$} \\
\hline \multicolumn{3}{|c|}{ Compare su listado con la siguiente ruta propuesta: } \\
\hline $\begin{array}{l}\text { Regiones de donde llegaron los pobladores } \\
\text { colombianos a CR }\end{array}$ & Épocas de mayor migración & $\begin{array}{l}\text { Cantidad de habitantes de origen } \\
\text { colombiano en CR }\end{array}$ \\
\hline Razones de la migración & $\begin{array}{l}\text { Actividades socioeconómicas de la } \\
\text { comunidad, al inicio y en la actualidad }\end{array}$ & $\begin{array}{l}\text { Formas de convivencia con el } \\
\text { resto del país }\end{array}$ \\
\hline
\end{tabular}

Nota: Elaboración propia como parte de la planificación docente.

Figura 2: Mediación para la creación de preguntas generadoras. Proyecto interdisciplinario (Español/Estudios Sociales), sexto grado, noviembre 2018

\begin{tabular}{|l|l|}
\hline \multicolumn{2}{|c|}{ Indicaciones para empezar la investigación } \\
\hline 1. Lea los siguientes temas y escoja uno en el cual desea investigar. Resalte el tema con un color a su gusto. \\
\hline Poblaciones víctimas del nazismo, además de la comunidad judía & Tradiciones y costumbres húngaras \\
\hline Operación Barbarroja & Terapia para sobrevivientes de eventos violentos \\
\hline 2. Plantee una pregunta generadora para su investigación. & \\
\hline 3. Ahora trace su ruta de investigación. Escriba varias preguntas que le ayuden a encontrar respuestas para su pregunta generadora. \\
\hline 1. \\
\hline 2. \\
\hline 3. \\
\hline 4. \\
\hline
\end{tabular}

Nota: Elaboración propia como parte de la planificación docente. 
La elaboración de estas guías de trabajo es, en realidad, la primera fase de la mediación. Lo que se lleva a cabo en el aula es todo un laboratorio o taller de preguntas generadoras. Particularmente en este contexto, se prefiere el término de laboratorio, ya que las experiencias se pueden caracterizar por aquella vivencia conocida de prueba yerror. Es una vivencia que requiere diálogo entre la persona que media el proceso y quienes crean sus preguntas. Un diálogo que puede darse en forma oral, mientras realizan sus trabajos y se animan a ir compartiendo sus pasos. Pero en otras situaciones, ese diálogo deberá darse en forma escrita y a distancia. Por eso es muy importante que este tipo de proyectos reciba avances de evaluación formativa.

Como las familias, cuando los individuos pequeños dan sus primeros pasos, están atentas a dar ese andamiaje necesario, de igual manera la mediación pedagógica invita al personal docente a dar observaciones al trabajo de sus estudiantes, en distintos momentos del proceso. Además, se debe tomar en cuenta que los ritmos de aprendizaje son diversos, que hay personas que no optan por expresar sus dudas frente al grupo, pero también tienen derecho a la mediación y el apoyo. De ese primer encuentro del grupo con las preguntas generadoras, presentamos unas muestras: ¿Cómo sucedió la Operación Barbarroja y qué consecuencias económicas trajo? (sexto grado, primaria) ¿Cómo ha sido el proceso con el que siguió adelante la comunidad judía en Hungría, después de la Segunda Guerra Mundial? (sexto grado, primaria) ¿Qué procesos de vida pasó Anna Sokolow durante los años de la Segunda Guerra Mundial? (sexto grado, primaria)

La construcción de esa última pregunta tuvo un detalle particular: para que la persona concretara lo que quería conocer, precisó de investigación exploratoria previa, por lo cual buscó fuentes en internet, conversó con informantes que mantenían cercanía con el tema fuera de aula, hasta llegar al nombre de Sokolow para crear su interrogante inicial. Esa es la curiosidad que se busca rescatar en este tipo de mediación, la que representa deseo de aprender y disfrute durante el camino. "Esas pretensiones de transformación de las sociedades adquiere manifestación específica y propia en el campo de la educación y la pedagogía bajo dispositivos y formas particulares en el campo de las metodologías" (Mejía, 2011, p. 91). La transformación de las pequeñas sociedades en las aulas hacia comunidades de personas aprendientes, de sociedades "dodiscentes" al decir de Freire y Faundez (2013), requiere nuevas metodologías, y no las técnicas tradicionales que tanto se aferran a los procesos educativos aún para buscar resultados distintos.

De nuevo se resalta la necesidad de mediación y guía en el proceso de construcción. Durante estas intervenciones, es recomendable utilizar también la pedagogía de la pregunta. En aquellos aspectos donde es necesario que el estudiantado haga un replanteamiento de sus propias ideas, la mediación puede darse a través de preguntas dirigidas, para guiarles en ese proceso de pensamiento. Por tanto, se debe evitar cualquier corrección de manera directa al trabajo ya que, como mencionan León-León y Zúñiga-Meléndez (2019), este tipo de prácticas docentes "no [permiten] un aprendizaje integral y permanente en el individuo; de tal manera que no se da un desarrollo del pensamiento reflexivo y crítico de la realidad inmediata" (p. 18). 
http://doi.org/10.15359/ree.25-2.21

http://www.una.ac.cr/educare

educare@una.ac.cr

Plantear preguntas implica activar procesos de los cuales, quizás, no somos conscientes. Involucra atención, descarte de algunos criterios, profundización en otros, escritura y reescritura de la idea planteada. Si el ejercicio es en equipos de trabajo, o la actividad ha sido planificada para involucrar a todo un colectivo, se abren procesos dialógicos y momentos de debate, donde las personas discutirán y negociarán para lograr la creación esperada. El diálogo fomentará otras habilidades importantes dentro del pensamiento crítico, como lo son la argumentación y el contra argumento. Estas ideas permiten observar la riqueza de la que se priva a las personas estudiantes cuando se corrige directamente su producción, en este caso, la de preguntas generadoras. En lugar de esa corrección, en lo que debería estar enfocada la mediación pedagógica es en ayudarles "a reformular la pregunta. De este modo, el educando aprende formulando la mejor pregunta" (Freire y Faundez, 2013, p. 72).

\section{Reflexión pedagógica. Dimensiones de la mediación pedagógica}

La teoría acerca de la mediación pedagógica, en estudios como los de Gutiérrez Pérez y Prieto Castillo (2004), Prieto Castillo (2000) y Tébar Belmonte (2017), permite ir definiendo tres importantes dimensiones que deben considerarse al planificar y desarrollar el trabajo con los distintos colectivos. Estas mismas dimensiones pueden ser algunos de los puntos de análisis y reflexión para sistematizar las experiencias compartidas, en el proceso de construcción de saberes. Las dimensiones son:

- del hacer conceptual

- del hacer discursivo

- del hacer aplicativo

\section{Dimensión del hacer conceptual}

Desde esta dimensión, la mediación pedagógica busca que las personas participantes desarrollen y fortalezcan sus habilidades de pensamiento; sean capaces de analizar su realidad, su entorno, y dentro de ese marco, los contenidos curriculares que siguen presentes. En esta dimensión, como elemento fundante, se considera el análisis de causas y consecuencias, como una estrategia de pensamiento que activa procesos donde esos posibles resultados lleguen a ser previstos. En una sociedad que ha construido y vive el contexto de la rapidez en los accesos, tanto a la información como a la desinformación, es de carácter crítico el fortalecimiento de esas dimensiones dentro de las aulas de enseñanza media. En esta etapa de la vida de las personas, la mediación pedagógica se ve estimulada por los cuestionamientos propios de la adolescencia, y a su vez la mediación orienta esos procesos mentales hacia la deconstrucción, tanto de saberes como de procesos: la deconstrucción de sus realidades. 
Analizando las mediaciones propuestas en esta sistematización, desde esta dimensión del hacer conceptual, se puede encontrar evidencias en dos de las preguntas generadoras construidas por estudiantes: ¿Cómo se manifiestan las ideas de La llustración en el desarrollo de la Revolución Francesa, de modo que se afectaron otras monarquías? (séptimo año) ¿Qué hizo o qué no hizo el gobierno local para que nadie lo recuerde? (octavo año)

En el caso de la pregunta construida en colectivo por el grupo de séptimo año, se trata de una pregunta generadora que orientó todo el proyecto a una búsqueda de relaciones de causas y consecuencias, de hechos vinculados en los procesos históricos estudiados durante el proyecto. No se crearon preguntas del tipo ¿qué fue la Revolución Francesa? o ¿qué ideas se propusieron en La llustración?; el proceso de mediación, sumado a los procesos de aprendizaje anteriores -ya descritos- enfocados en la creación de esta categoría de preguntas, suministró herramientas cognitivas para que lograran un producto dirigido a la búsqueda de relaciones causales.

En cuanto a la pregunta propia de octavo año, además de llevar hacia un análisis causal, relacionado con las funciones específicas de los gobiernos locales costarricenses, se puede ver en su planteamiento los razonamientos de las personas adolescentes. La necesidad de trascendencia, de la construcción del yo en medio del colectivo, de la búsqueda de la identidad. Esos procesos se ven reflejados en la construcción de la pregunta, solo que trasladados a la figura del gobierno local.

\section{Dimensión del hacer discursivo}

Esta dimensión se centra en el fomento de las habilidades de comunicación en el estudiantado. Dichas habilidades bien se pueden atender desde cuatro áreas del lenguaje: recepción y producción, tanto escrita como oral. Además, se consideran en este ámbito de la mediación todos los recursos relacionados con argumentación razonada. Como ya se expuso párrafos atrás, los procesos de construcción de preguntas generadoras, ya sea en células de trabajo o en colectivo, no solamente fomentan, sino que se basan en estas habilidades. El mismo proceso de construir una pregunta generadora establece condiciones vinculadas al hacer discursivo. Esas condiciones pasan por la estructura de la pregunta, la forma en que se presente, reescribirla en varias oportunidades hasta que logre comunicar esa necesidad de conocimiento de las personas. Como muestra de la presencia de esta dimensión, se tiene una pregunta creada de manera colectiva por un grupo de octavo año: ¿Qué medidas podría adoptar el TSE [Tribunal Supremo de Elecciones] para reducir o evitar el porcentaje de abstencionismo actual en Costa Rica? (octavo año)

Esta pregunta movilizó el proyecto hacia una línea de trabajo dentro del hacer discursivo, en donde se pudieron observar distintas propuestas de las personas participantes, discusión entre pares y momentos de reflexión muy interesantes. En una de las etapas del proyecto, el estudiantado presentó por escrito las ideas, con argumentos que pudieran dar validez a las 
http://doi.org/10.15359/ree.25-2.21

http://www.una.ac.cr/educare

educare@una.ac.cr

mismas, ante su colectivo. Los escritos dejaron evidencias de diálogos intra personales, que suscitaron lugar al análisis de beneficios y perjuicios que podrían surgir, relacionados con la implementación de sus ideas.

\section{Dimensión del hacer aplicativo}

Esta dimensión de la mediación pedagógica busca el sentido pragmático del quehacer para la construcción del aprendizaje. Pero, desde la postura de la mediación, no se considera ese pragmatismo en un sentido de la actividad en sí misma, pues se corre el riesgo de caer en un activismo sin reflexión. La dimensión del hacer aplicativo motiva a que las distintas habilidades fortalecidas, tanto en el ámbito conceptual como en el discursivo, puedan ser empleadas en la transformación de realidades. Ahora bien, esta dimensión incluye las habilidades que se desarrollan y son necesarias en los procesos de investigación: observación, experimentación, análisis, reflexión crítica, proposición. Al repasar lo analizado, buscando las preguntas generadoras creadas por el estudiantado, se encuentran esas realidades sensibles de transformación.

Se puede empezar a concluir que la realidad inmediata que se transforma es la de sus propios colectivos de aprendizaje. Esta transformación surge desde el uso de la pregunta en ambientes pedagógicos, al alejarla del perfil inquisidor y poniendo distancia con el modelo de educación bancaria, para que pueda asumir su rol como el elemento que sintetiza las curiosidades de cada persona dentro del aula. Una transformación de cada profesional docente, que cede su monopolio en el uso y la orientación de las preguntas, para que sea el colectivo quien pregunte. Transformación, por tanto, de la persona estudiante, quien va asumiendo el rol protagónico desde las tres dimensiones de la mediación. Ese estudiantado que ya no debe esperar y aceptar la pregunta propuesta dentro de la planificación docente, porque ahora analiza, dialoga y construye con su colectivo. Un estudiantado que plantea preguntas, participa activamente en proyectos que involucran investigación y propone alternativas desde sus saberes.

\section{Para cerrar la reflexión y abrir nuevos procesos}

Con el fin de seguir el hilo de las primeras conclusiones expuestas, se sintetiza que la pregunta generadora es el elemento de apertura en la metodología basada en proyectos, que resume a modo de interrogante, lo que el grupo participante busca construir como conocimiento durante el tiempo que se estime para el proceso. Se espera que sea creada por el estudiantado, en la primera fase del proyecto, con mediación pedagógica de la persona docente. Para facilitar ambos roles, la planificación de esa etapa debe incluir estrategias diversas que permitan desarrollar destrezas necesarias. Esta pregunta se caracteriza por ser abierta: permite una gama diversa de respuestas. Abre la posibilidad para que el colectivo formule un entramado de interrogantes que faciliten el proceso de construcción de los aprendizajes. Su principal objetivo pedagógico es activar la naturaleza curiosa del estudiantado, para motivar a que asuma protagonismo en el aula. 
La sistematización de experiencias registró procesos donde estudiantes de doce a catorce años de edad fueron capaces de producir preguntas generadoras pertinentes, adecuadamente estructuradas y que funcionaron como elemento orientador en el desarrollo de los proyectos. La creación de preguntas generadoras puede realizarse de forma individual o colectiva. Además de los procesos cognitivos que se estimulan durante la creación misma, se fortalecen otros aprendizajes, ligados a las estrategias empleadas. Se pudo observar el fortalecimiento de destrezas en pensamiento crítico, argumento razonado, cultura dialógica, participación consciente. En los procesos pedagógicos de análisis y reflexión, se pudo encontrar que los espacios para crear preguntas generadoras, responden a las tres dimensiones de la mediación: conceptual, discursiva y aplicativa.

Esta investigación permite reflexionar sobre el recurso de la pregunta y su significante en las relaciones de poder en las aulas de enseñanza secundaria. El concepto que tenga cada persona docente acerca del uso de la pregunta, la comunicación que construye a través de ella y la intención que subyace al formularla, marcan diferencias en los roles que asume cada participante en la dinámica del aula. En el momento en que son dadas las condiciones para que ellos y ellas cuestionen, y los encuentros cotidianos se organicen para construir respuestas a las preguntas que sí hicieron, se está trabajando por la transformación de esa convivencia académica.

Los espacios de reflexión pedagógica, provocados por cada una de las sistematizaciones, permite dar cuenta de ciertas recomendaciones que puedan ser continuadas por otras personas docentes, interesadas en la temática, sea para aplicación o también desde la investigación. Dichas recomendaciones se presentan seguidamente:

- Mirar el uso pedagógico de la pregunta generadora como puente, ya sea entre saberes previos, entre seres humanos, dentro y fuera del aula. De igual forma, entre el proceso de aprendizaje y la realidad global en la que se enmarca, lo cual permite invitar al estudiantado a participar en procesos de problematización.

- Ese puente se puede construir dentro de una metodología de aprendizaje basado en proyectos, en el tanto y cuanto las preguntas generadoras sean creadas por el estudiantado. En este caso, las etapas del proyecto deben considerar espacios para la creación de dichas interrogantes.

- Plantear espacios pedagógicos para la construcción de preguntas en forma colaborativa. Además de incentivar el pensamiento crítico, promueve la construcción de conocimiento compartido.

- La construcción de preguntas generadoras puede desarrollarse en un formato de laboratorio de preguntas, donde se fomente el derecho a la prueba y al error. Por tanto, de la persona docente se requiere requiere prácticas de mediación, más que corrección. Se propone usar la pregunta, en este caso desde la docencia, para que puedan descubrir sus oportunidades de mejora. 
http://doi.org/10.15359/ree.25-2.21

http://www.una.ac.cr/educare

educare@una.ac.cr

La creación de preguntas generadoras por parte de la adolescencia, dentro de su educación formal, es un valioso recurso para despertar la curiosidad y el deseo de investigar; para que no vean este proceso como algo lejano a su realidad. Además, permite que estos grupos de estudiantes vayan desarrollando prácticas que luego puedan utilizar, al crear preguntas de investigación, rutas metodológicas, y enfrentar otros retos académicos. Finalmente, como el proceso de investigación pedagógica debería ser algo permanente, con el fin de seguir buscando oportunidades de cambio y crecer en ellas, este trabajo da oportunidad para abrir otras líneas, centradas en el uso de la pregunta generadora en relación con los procesos metacognitivos; la representación de la voz adolescente en la educación a través de la creación de este tipo de preguntas; $y$, siguiendo el hilo teórico de la metodología basada en proyectos, ofrecer más información de estos proyectos sistematizados, y cuál fue su evolución luego de creada la pregunta inicial.

\section{Declaración de Material complementario}

Este artículo tiene disponible, como material complementario:

-La versión preprint del artículo en https://doi.org/10.5281/zenodo.4041840

\section{Referencias}

Díaz Barriga Arceo, F. y Hernández Rojas, G. (2010). Estrategias docentes para un aprendizaje

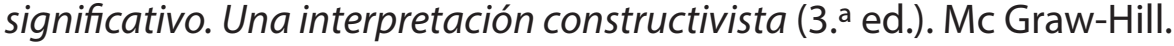

Eger, E. (2018). La bailarina de Auschwitz. Planet.

Fallas, C. L. (2012). Marcos Ramírez (3. a ed.). Editorial Costa Rica.

Freire, P. y Faundez, A. (2013). Por una pedagogía de la pregunta, crítica a una educación basada en respuestas a pregunta inexistentes. Siglo Veintiuno.

Gutiérrez Pérez, F. y Prieto Castillo, D. (2004). La mediación pedagógica. Apuntes para una educación a distancia alternativa (10. ${ }^{\mathrm{a}}$ ed.). Ediciones La Copia Fiel.

León León, G. (2014). Aproximaciones a la mediación pedagógica. Revista Calidad en la Educación Superior, 5(1), 136-155. https://dialnet.unirioja.es/servlet/articulo?codigo $=5580842$

León-León, G. y Zúñiga-Meléndez, A. (2019). Mediación pedagógica y conocimientos científicos que utilizan una muestra de docentes de ciencias de noveno año de dos circuitos del sistema educativo costarricense, para el desarrollo de competencias científicas. Revista Electrónica Educare, 23(2) 1-24. https://doi.org/10.15359/ree.23-2.5 
http://doi.org/10.15359/ree.25-2.21

Mejía, M. R. (2011). Educaciones y pedagogías críticas desde el sur (Cartografías de la educación popular). CEAAL. https://issuu.com/siembrasocialismo/docs/125229865-pedagogias-criticas-desde

Mejía, M. R. y Manjarrés, M. E. (2011). La investigación como estrategia pedagógica. Una construcción de cultura ciudadana y democrática desde el sur. Prograf.

Prieto Castillo, D. (2000). Mediación pedagógica y contexto digital. Revista Universidad Pontificia Bolivariana, 48(147), 27-38. https://revistas.upb.edu.co/index.php/upb/article/ view/1932/1730

Real Academia Española. (2014). Diccionario de la lengua española (23. ${ }^{a}$ ed.). Espasa Calpe.

Rocerau, M. C. y Vilanova, S. L. (2008). El diálogo en el quehacer matemático: Su valor como recurso. Revista Iberoamericana de Educación, 47(4), 1-10. https://doi.org/10.35362/ $\underline{\text { rie4742274 }}$

Rodríguez García, H. (2016). Hacia una genealogía de la educación y la pedagogía. Saber Revista Multidisciplinaria del Consejo de Investigación de la Universidad de Oriente, 28(4), 851-864. http://ve.scielo.org/scielo.php?script=sci issuetoc\&pid=1315016220160004\&lng=es\&nrm=iso

Tébar Belmonte, L. (2017). La función mediadora de la educación. Foro Educacional, 28, 79-98. https://doi.org/10.29344/07180772.28.790

Thomas, J. W. (2000). A review of research on project-based learning. AutoDesk Foundation. 